\title{
Efeitos da prótese de polipropileno colocada por inguinotomia no espaço pré-peritoneal, em cães. Avaliação laparoscópica e microscópica ${ }^{1}$
}

\author{
Robério Silva Melo \\ Alberto Goldenberg ${ }^{3}$ \\ Saul Goldenberg ${ }^{4}$ \\ Antenor T. Leal ${ }^{5}$ \\ Alexandre Magno ${ }^{6}$
}

\begin{abstract}
Melo RS, Goldenberg A, Goldenberg S, Leal AT, Magno A. Efeitos da prótese de polipropileno colocada por inguinotomia no espaço pré-peritoneal, em cães: avaliação laparoscópica e microscópica. Acta Cir Bras [serial online] 2003 Jul-Ago;18(4). Disponível em URL: http://www.scielo.br/acb.
\end{abstract}

RESUMO - Objetivo: Observar os efeitos produzidos pela prótese de polipropileno no espaço préperitoneal. Métodos: 10 cães $(n=10)$, adultos e sem raça definida, foram submetidos a inguinotomia bilateral, nas quais se colocou uma prótese em um dos lados. Na região contralateral, o procedimento foi o mesmo, sem a colocação da prótese, servindo como controle. Após 30 dias os animais foram submetidos a uma videolaparoscopia e foi realizada a avaliação macroscópica por via intraperitoneal, além do registro das alterações histológicas das duas regiões inguinais. Resultados: Três (03) animais apresentaram aderências epiplóicas no local de implantação da prótese de polipropileno. Nenhum animal apresentou aderência no lado B (sem prótese). As alterações microscópicas no lado A (com prótese) caracterizaram-se pela proliferação de tecido conjuntivo fibroso denso, além da escassa presença de células gigantes multinucleadas, comprovando uma reação inflamatória de leve intensidade. Conclusão: A prótese de polipropileno induz a formação de aderências em $30 \%$ dos animais, quando colocada no espaço pré-peritoneal em cães.

DESCRITORES - Aderências. Laparoscopia. Cães. Prótese.

\section{Introdução}

Observando-se que o reparo cirúrgico da hérnia inguinal é a operação mais freqüentemente executada pela cirurgia geral ${ }^{(1)}$ e continuando uma linha de pesquisa desenvolvida na pós-graduação de gastroenterologia cirúrgica da Escola Paulista de Medicina - Unifesp, que estuda a utilização de próteses na correção dos defeitos da parede abdominal ${ }^{(2,3)}$ realizou-se este estudo para observar efeitos da prótese de polipropileno colocada por inguinotomia no espaço pré-peritoneal, em cães. Apesar das hérnias acometerem mais o homem, também podem aparecer nos mamíferos quadrúpedes como demonstraram Waters e col. ${ }^{(4)}$ em estudo retrospectivo de tratamento cirúrgico de 35 cães com hérnias da região inguinal. Dentre as próteses usadas na correção de hérnias, o material mais empregado ainda é o polipropileno ${ }^{(5)}$ e, à medida que estas têm sido cada

1. Resumo de Tese de Mestrado em Gastroenterologia Cirúrgica da Universidade Federal de São Paulo - Escola Paulista de Medicina (UNIFESP-EPM).

2. Professor Assistente do Departamento de Cirurgia da Escola de Ciências Médicas de Alagoas.

3. Doutor, Professor Adjunto da Disciplina de Cirurgia Gastroenterológica do Departamento de Cirurgia da UNIFESP-EPM.

4. Professor Titular do Departamento de Cirurgia da UNIFESP-EPM. Pesquisador 1A do CNPq.

5. Professor Titular do Departamento de Patologia da Escola de Ciências Médicas de Alagoas.

6. Doutorando da Escola de Ciências Médicas de Alagoas. 
vez mais utilizadas, tem-se o receio de que as complicações decorrentes do seu emprego tornar-se-ão mais freqüentes ${ }^{(6)}$.

Numerosos estudos experimentais descreveram a formação de aderências em animais que realizaram a correção da região inguinal pela técnica intraperitoneal laparoscópica, ${ }^{(7,8 ; 9 ; 10)}$; porém, alguns autores ${ }^{(11,12)}$ relataram em anima nobili complicações intraperitoneais, como fístulas e obstrução intestinal, provocadas pelo uso da prótese de polipropileno colocada por abordagem inguinal anterior, fatos que nos motivaram à presente pesquisa, tendo como objetivo investigar os efeitos laparoscópicos e histológicos da prótese de polipropileno, colocada no espaço pré-peritoneal da região inguinal por via de acesso anterior, em cães.

\section{Métodos}

Foram utilizados 10 cães, adultos, sem raça definida (canis familiares), fêmeas, com peso variando de 08 a $12 \mathrm{Kg}$. Os cães eram do Biotério da Escola de Ciências Médicas de Alagoas - Universidade de Ciências da Saúde (ECMAL-UNCISAL), e os procedimentos cirúrgicos obedeceram aos critérios, normas técnicas e direitos internacionais de pesquisa em animais do comitê de ética do Colégio Brasileiro de Experimentação Animal (COBEA) ${ }^{(13)}$ com aprovação do conselho de Ética da mesma instituição.

\section{Procedimentos}

Os animais foram numerados de 1 a 10 e sorteados em relação ao procedimento cirúrgico e ficaram em jejum pré-operatório por 12 horas. Na pré-anestesia, utilizou-se a quetamina na dose de 50 a $100 \mathrm{mg}$ ( 1 a 2 $\mathrm{ml}$ ) por via intramuscular, dez minutos antes do procedimento. $\mathrm{O}$ antibiótico foi administrado (Penicilina G Benzatina - 1.200.000 ui - Intramuscular). Após 10 minutos, o animal foi levado a mesa cirúrgica e realizouse a contenção dos quatro membros, mantendo-se o animal em posição dorsal $\mathrm{Na}$ anestesia, por venóclise localizada na pata dianteira, utilizou-se o tiopental sódico na dose de $8 \mathrm{mg} / \mathrm{kg} /$ peso (miligramas/kilogramas de peso) diluído em $25 \mathrm{mg} / \mathrm{ml}$, seguido de Cloridrato de Fentanila (30 a $100 \mathrm{mg} / \mathrm{kg} /$ peso) na dose de 03 a 05 $\mathrm{ml}$, para a manutenção da anestesia. $\mathrm{O}$ animal foi submetido à passagem de tubo orotraqueal $n^{\circ} 7$ de uso humano e mantido em ventilação manual com oxigênio a $100 \%$, na concentração de dois litros por minuto (min). Foi realizada a raspagem dos pêlos da região abdominal e a anti-sepsia da pele das regiões inguinais bilateralmente com polivinilpirrolidona-iodo (PVPI) a $10 \%$. A seguir foram colocados os campos operatórios e o ato operatório realizado com técnica asséptica.

\section{Dissecção da região inguinal}

Alternou-se o lado de início da inguinotomia a cada animal e esta foi em sentido oblíquo, de $3 \mathrm{~cm}$ de extensão, $2 \mathrm{~cm}$ acima do ligamento inguinal, com abertura da pele e da tecido subcutâneo. Após identificação do ligamento inguinal, incisava-se a aponeurose do músculo obliquo externo, tendo-se o acesso ao canal inguinal. A parede posterior da região inguinal era aberta progressivamente, incisando-se com bisturi o músculo obliquo externo e a fáscia tranversal, expondo o peritôneo parietal..

Foi utilizada prótese de polipropileno plana, de tamanho original de $30 \times 30 \mathrm{~cm}$, previamente cortada em fragmentos idênticos de 3,5 x 4,0 cm, acondicionados em papel grau cirúrgico e esterilizados previamente em peróxido de hidrogênio durante 45 minutos. A decisão da implantação da prótese de polipropileno na região inquinal foi realizada por escolha aleatória de dois recipientes fechados, idênticos externamente, opacos, sendo que apenas um deles continha a prótese, que foi implantada no primeiro lado operado. Caso o recipiente não contivesse a prótese, realizava-se a sutura dos planos sem prótese naquele lado, colocando-se a prótese no outro lado. Como referência anatômica, foi identificada nesta área a artéria epigástrica caudal profunda, onde foi posta a prótese sobre o peritôneo, e fixada com quatro pontos de fio de polipropileno 4-0 ao músculo oblíquo interno e a fáscia transversal. A seguir suturava-se com pontos separados a aponeurose do músculo obliquo externo com o mesmo fio, assim como o tecido celular subcutâneo e a pele. Na região inguinal contra-lateral (lado B - controle) foi feita a dissecção e exposição semelhante ao outro lado, com a diferença de que não foi utilizada a prótese de polipropileno, procedendo-se a sutura dos planos, com pontos separados de fio de propropileno 4-0, progressivamente até a pele.

\section{Cuidados pós-operatórios}

Após término do procedimento operatório, retirouse o acesso venoso e os animais foram recuperados da anestesia em canil individual, liberando-se a dieta no próprio dia do procedimento, permanecendo em observação diária no próprio biotério por 30 dias, sob cuidados do veterinário responsável. 


\section{Videolaparoscopia}

Foi realizada 30 dias após o primeiro procedimento e obedecia a toda sequiência de jejum e anestesia, conforme já descrito no $1^{\circ}$ procedimento. $\mathrm{O}$ acesso à cavidade abdominal se deu por duas punções:

A primeira incisão foi realizada na região umbilical, com $10 \mathrm{~mm}$ de extensão, na linha mediana ventral, onde foi introduzido o trocarte de $10 \mathrm{~mm}$, para passagem da óptica laparoscópica, destinada à visibilização do cavidade abdominal. A segunda incisão foi de $5 \mathrm{~mm}$ de extensão, $3 \mathrm{~cm}$ à direita da região umbilical ( $1^{\circ}$ punção), com colocação de trocarte de $5 \mathrm{~mm}$ e uso de bastão palpador laparoscópico de $5 \mathrm{~cm}$ para auxílio na manipulação das possíveis aderências intracavitárias.

Utilizou-se uma óptica de $10 \mathrm{~mm}$ com ângulo de 45 graus conectada a uma microcâmara. A cavidade abdominal foi insuflada com $\mathrm{CO} 2$ e mantida em uma pressão de $12 \mathrm{mmHg}$. O animal foi mantido sob anestesia geral com as drogas anteriormente citadas. Procedeu-se ao inventário da região pélvica, visibilizando-se as duas regiões inguinais, tendo-se como referência a identificação da artéria epigástrica caudal. O registro das imagens foi realizado por aparelho de vídeocasseteVHS. Ao final da laparoscopia, realizou-se uma incisão na linha mediana ventral, da cicatriz da laparoscopia ao tubérculo púbico, com acesso as regiões inguinais na sua face interna, procedendo-se à excisão bilateral de dois fragmentos de peritônio de $2 \mathrm{~cm}$ de cada lado. Cada peça foi imersa em $20 \mathrm{ml}$ de solução tamponada de formaldeído a $10 \%$ e foram encaminhadas ao serviço de patologia. Terminados os procedimentos cirúrgicos, e ainda anestesiados, os animais foram submetidos à eutanásia, com administração de $20 \mathrm{ml}$ de cloreto de potássio a $10 \%$, por via endovenosa.

\section{Variáveis estudadas}

\section{Aderências}

Conceituou-se como aderência a fixação anormal de alguma estrutura intraperitoneal ao peritôneo parietal no local de implantação da prótese ou no lado controle (sem prótese), verificando-se aos 30 dias, pelo mesmo avaliador, a presença ou não de aderências epiplóicas ou viscerais nas duas regiões inguinais.

Uma vez identificadas, foi utilizada a seguinte escala de graduação qualitativa ${ }^{(14)}$ :

Grau 0 = sem aderências;
Grau 1 = aderências mínimas facilmente desfeitas com dissecção romba;

Grau 2 = aderências moderadas desfeitas com dissecção romba agressiva;

Grau 3 = aderências densas que requerem dissecção cortante.

\section{Reação inflamatória aguda-crônica}

A avaliação microscópica foi realizada pelo Departamento de Patologia da Santa Casa de Misericórdia de Maceió, pelo mesmo anátomo-patologista. Os dois fragmentos, retirados de cada região inguinal dos animais, foram colocados em solução tamponada de formaldeído a $10 \%$ e submetidos a desidratação em álcool etílico, diafanização pelo xilol, inclusão em blocos de parafina e microtomia em cortes de 6 micrômetros de espessura. Estes cortes foram estendidos em banhomaria, colados em lâmina de vidro e corados pela Hematoxilina-Eosina (HE) e analizadas em aumentos de dez a quarenta vezes.

Foram verificadas a presença e a intensidade da reação inflamatória e anotados os elementos celulares predominantes: leucócitos polimorfonucleares neutrófilos, linfócitos; células gigantes, fibroblastos e fibras colágenas, além da interação das fibras da prótese de polipropileno aos tecidos contíguos, e anotados os dados na ficha de protocolo.

A reação inflamatória aguda/crônica foi classificada de acordo com uma escala qualitativa ${ }^{(9)}$ :

Ausente $=$ ausência de fibrose ou células gigantes;

Leve $=$ fibrose densa com escassa presença de células gigantes;

Moderada $=$ fibrose com poucos polimorfonucleares e células gigantes;

Intensa $=$ fibrose frouxa com grande número de polimorfonucleares e células gigantes.

\section{Resultados}

As operações propostas foram realizadas adequadamente, não tendo ocorrido qualquer dificuldade técnica, bem como não ocorreram complicações transoperatórias. Os animais apresentaram boa cicatrização, sem saída de secreção nas feridas operatórias.

\section{Avaliação vídeo-laparoscópica das aderências}

No Lado "A" (com prótese) três animais apresentaram a formação de aderências epiplóicas ao peritônio sobreposto à prótese de Polipropileno, tendo elas sido classificadas como grau 2 (dois casos) e grau 1(um caso). Figuras 1, 2, 3 e 4. 


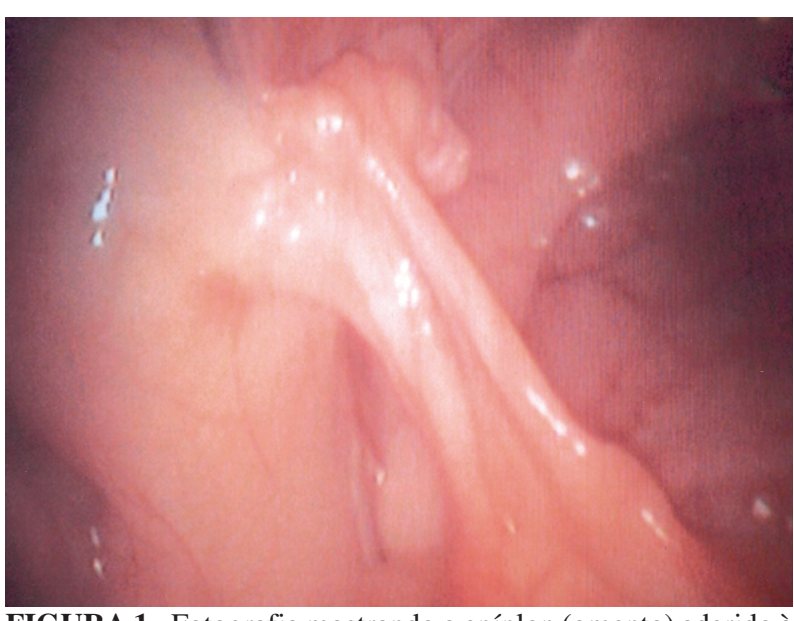

FIGURA 1 - Fotografia mostrando o epíplon (omento) aderido à prótese de polipropileno na região inguinal (Lado A - Com prótese). Animal 2 - Lado esquerdo

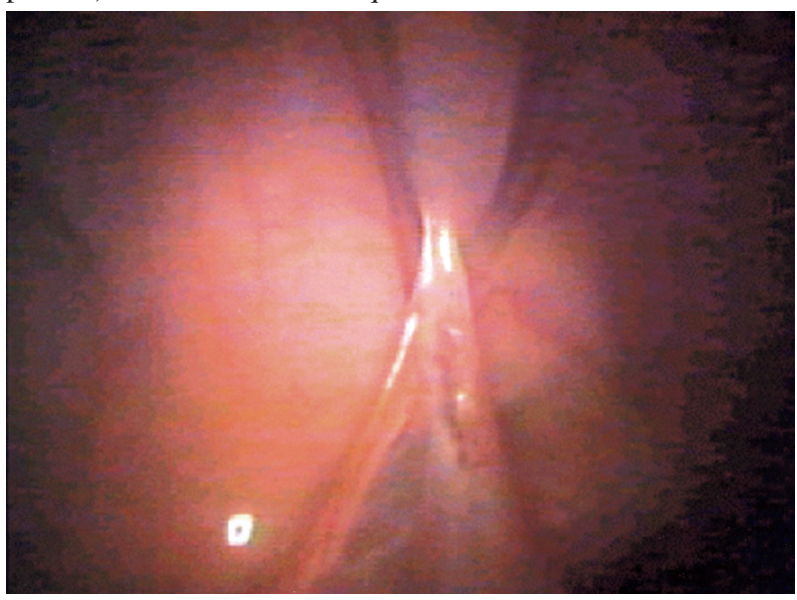

FIGURA 3 - Fotografia mostrando o omento aderido à prótese de polipropileno na região inguinal (Lado A). Animal 9 - Lado direito.

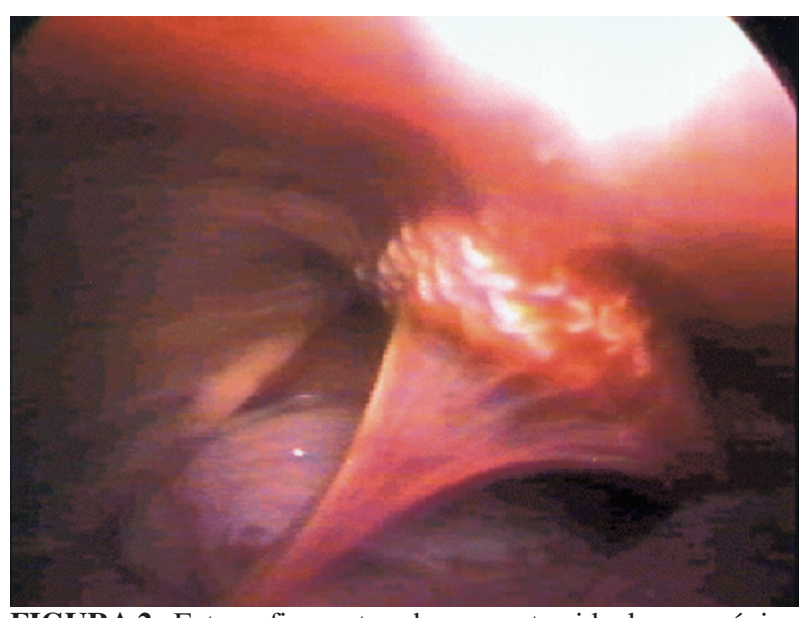

FIGURA 2 - Fotografia mostrando o aspecto videolaparoscópico do epíplon (omento) aderido à prótese de polipropileno na região inguinal. (Lado A - Com prótese). Animal 7 - Lado direito.

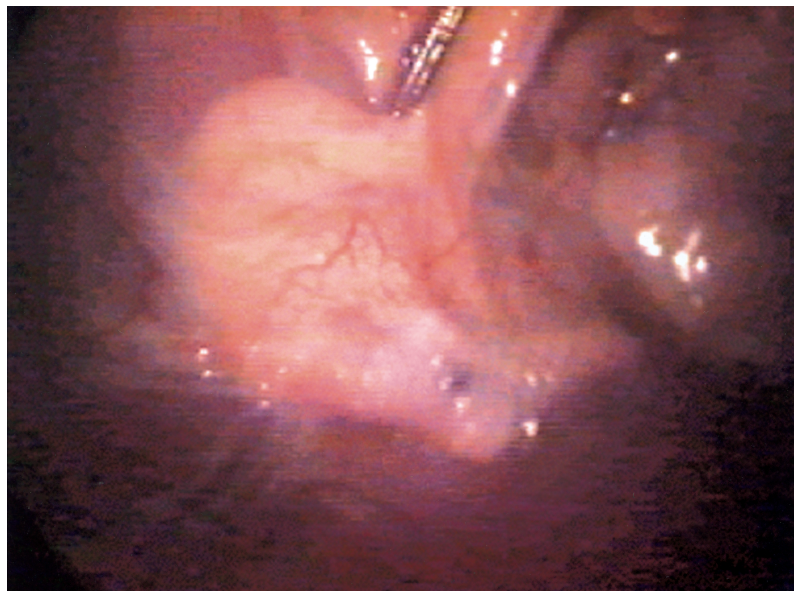

FIGURA 4 - Fotografia mostrando o aspecto videolaparocópico da prótese sob o peritôneo e sem aderência. (Lado A). Animal 10 - Lado esquerdo.

TABELA 1 - Avaliação laparoscópica das aderências dos lados A e B.

\begin{tabular}{llll}
\hline \multirow{2}{*}{ Aderência } & Lado & & \\
\cline { 2 - 4 } & $\mathrm{A}$ & $\mathrm{B}$ & \\
& $($ Com prótese $) \mathrm{n}=10$ & $\begin{array}{l}\text { (Sem prótese }) \\
\mathrm{n}=10\end{array}$ & $03(15 \%)$ \\
\hline Sim & $03(15 \%)$ & $00(00 \%)$ & $17(85 \%)$ \\
Não & $07(35 \%)$ & $10(50 \%)$ & $20(100 \%)$ \\
\hline Total & $10(50 \%)$ & $10(50 \%)$ & \\
\hline
\end{tabular}

Os dados encontrados dispensaram análise estatística

TABELA 2 - Avaliação das aderências do lado com prótese. (Lado A)

\begin{tabular}{llll}
\hline \multirow{3}{*}{ Aderência } & Lado & \\
\cline { 2 - 4 } & $\begin{array}{l}\text { Direito } \\
(\mathrm{n}=5)\end{array}$ & $\begin{array}{l}\text { Esquerdo } \\
(\mathrm{n}=5)\end{array}$ & Total \\
\hline Sim & $02(20 \%)$ & $01(10 \%)$ & $03(30 \%)$ \\
Não & $03(30 \%)$ & $04(40 \%)$ & $07(70 \%)$ \\
\hline Total & $05(50 \%)$ & $05(50 \%)$ & $10(100 \%)$ \\
\hline
\end{tabular}

Os dados encontrados dispensaram análise estatística 


\section{Avaliação da intensidade da reação inflamatória agudo-crônica}

O estudo histológico do peritônio no lado A (com prótese), no trigésimo dia de pós-operatório, mostrou o predomínio da proliferação de fibrócitos acompanhados de fibras colágenas e colágeno; a presença de células gigantes multinucleadas foi escassa, comprovando uma reação inflamatória de leve intensidade.

No lado B (sem prótese) o estudo histológico do peritônio no trigésimo dia de pós-operatório mostrou ausência de reação inflamatória (Figura 5).

TABELA 3 - Intensidade da reação inflamatória aguda-crônica.

\begin{tabular}{|c|c|c|c|c|c|c|}
\hline \multirow[b]{2}{*}{ Reação Inflamatória } & \multicolumn{4}{|l|}{ Lado } & \multirow{2}{*}{\multicolumn{2}{|c|}{$\begin{array}{l}\text { Total } \\
(\mathrm{n}=20)\end{array}$}} \\
\hline & $\begin{array}{l}\text { Prótese } \\
(\mathrm{n}=10)\end{array}$ & & $\begin{array}{l}\text { Ser } \\
(\mathrm{n}=\end{array}$ & & & \\
\hline Ausente & 00 & $(00 \%)$ & 10 & $(50 \%)$ & 10 & $(50 \%)$ \\
\hline Sim-leve & 10 & $(50 \%)$ & 00 & $(00 \%)$ & 10 & $(50 \%)$ \\
\hline Total & 10 & $(50 \%)$ & 10 & $(50 \%)$ & 20 & $(100 \%)$ \\
\hline
\end{tabular}

Os resultados encontrados dispensaram análise estatística.

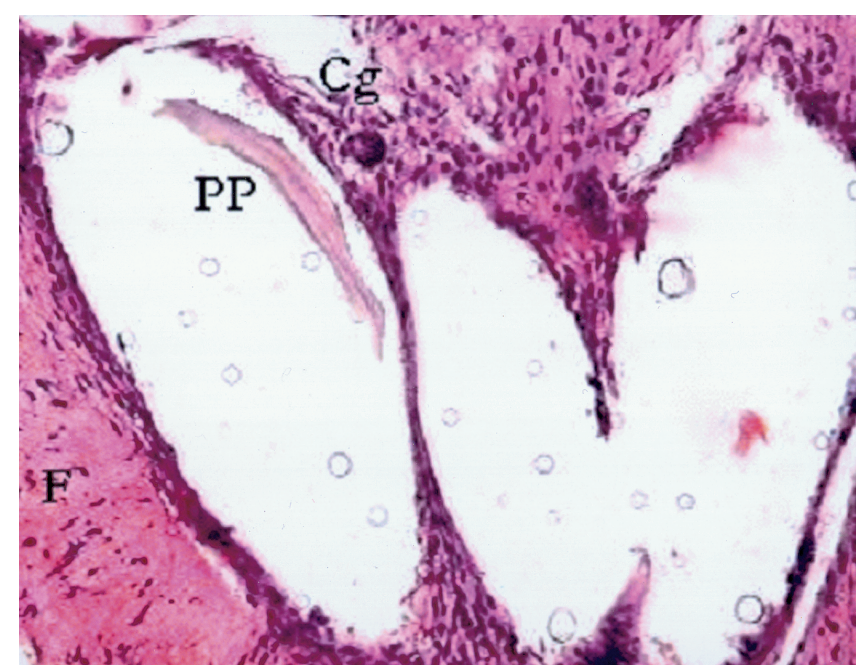

FIGURA 5 - Fotomicrografia mostrando reação inflamatória leve em torno dos orifícios onde estava a prótese de polipropileno (PP), dissolvida parcialmente pelo xilol; Observar presença de fibrose densa (F) e raras células gigantes multinucleadas $(\mathrm{Cg})$. Hematoxilina-Eosina (40x).

\section{Discussão}

Na intenção de investigar os efeitos intraperitoneais da prótese de polipropileno colocada por via de acesso anterior da região inguinal de cães, optou-se pela avaliação laparoscópica das aderências associada ao estudo das alterações histológicas dos tecidos adjacentes à prótese, visando obter-se subsídios macroscópicos corroborados pelos achados histológicos.

As próteses de polipropileno são compostas por fios monofilamentados dispostos em forma entrelaçada, são semi-rígidas, ligeiramente elásticas e a sua superfície é áspera, dificultando a migração sobre os tecidos ${ }^{(12)}$. As próteses de Prolene ${ }^{\circledR}$ formam poros pouco maiores de 620 mícras $(\mathrm{mm})$ e são similares às próteses de Marlex®, exceto pelo fato das primeiras terem poros menores ${ }^{(15)}$. Através destes poros, infiltram-se os fibroblastos, resultando na deposição de fibras colágenas, promovendo o processo de cicatrização através da integração aos tecidos ${ }^{(16)}$. As próteses com poros superiores a $100 \mathrm{~mm}$ permitem uma maior fibroplasia e angiogênese, além de facilitarem a passagem de células 
imunocompetentes, dificultando o aparecimento de processos infecciosos ${ }^{(17)}$

Com a introdução da prótese de polipropileno por USCHER ${ }^{(18)}$ quatro décadas atrás, além do uso de materiais de sutura melhores para fixação da prótese, que não eram então disponíveis, diminuiu a maioria das complicações indesejáveis, porém alguns autores atribuem à prótese de polipropileno maior incidência de aderências e fístulas ${ }^{(17 ; 6)}$, induzindo outros a utilizarem materiais como o PTFE-e ${ }^{(19 ; 20)}$, ou sobreposição de próteses ou tecidos absorvíveis sobre o polipropileno, evitando as complicações supracitadas ${ }^{(21)}$.

Alguns autores ${ }^{(22)}$ acreditam que a adesão do intestino ao biomaterial é a primeira fase da fístula intestinal relacionada à prótese, portanto, sua prevenção é lógica para a eliminação desta complicação; desse modo, advogam o uso de prótese de polipropileno coberta com metal laminado de PTFE, no lado do peritônio. Estas combinações com a propriedade seletiva de aderir à parede abdominal, porém poupando as vísceras, facilitariam cirurgias da parede abdominal, bem como hernioplastias laparoscópicas, principalmente por via intraperitoneal.Em relação à formação de aderências encontradas em três animais do lado com prótese, mesmo com peritônio íntegro no nosso experimento, JACKSON ${ }^{(23)}$ publicou que estas podem resultar de trauma mecânico e isquemia do peritônio, resultantes da presença da prótese, favorecendo a migração do omento em direção à área do dano peritoneal, caracterizando-se como a fase dinâmica do processo de cicatrização. Spelzini e col. ${ }^{(24)}$ operaram coelhos adultos em três grupos de 10 animais, usando um modelo próprio de hérnia da parede abdominal com dois tipos de próteses: polipropileno e politetrafluoroetileno expandido. Em seguimento pós-operatório de 30, 60 e 90 dias, observaram a macroscopia e microscopia, que o polipropileno provoca múltiplas aderências viscerais, desaconselhando sua implantação em contacto com as vísceras da cavidade abdominal.

Em três casos do lado onde foi implantada a prótese, no nosso estudo, ocorreram aderências do peritônio adjacente a prótese ao omento, tendo dois casos classificados como Grau $2{ }^{(9)}$, por terem exigido dissecção romba para serem desfeitas. ELLER e col. ${ }^{(10)}$ compararam, em suínos, a técnica de herniorrafia por videolaparoscopia transabdominal com a técnica de herniorrafia por inguinotomia. Utilizando dois grupos de 31 animais, em que a prótese de PTFE-e foi colocada no espaço pré-peritoneal, concluíram que há um risco de formação de aderências no método videolaparoscópico que não existe na herniorrafia convencional. Neste contexto, LAYMAN e col. ${ }^{(19)}$ realizaram 35 herniorrafias, pela técnica intraperitoneal vídeo-laparoscópica, em suínos, utilizando o PTFE-e e polipropileno, observaram pequena formação de aderências; porém, relataram complicações que chamavam atenção pela gravidade: uma torção testicular, duas recidivas com obstrução intestinal e uma obstrução intestinal por aderências em um animal que recebeu a prótese de polipropileno, tendo três animais morrido devido à obstrução intestinal. No Lado B (sem prótese) do nosso experimento, nenhum animal apresentou aderências, corroborando a idéia de que na ausência da prótese de polipropileno a possibilidade de aderência é remota.

A constatação de reação inflamatória leve no lado com prótese e a ausência de reação inflamatória no lado sem prótese do nosso experimento mostrou que a presença da prótese induziu a processo de cicatrização com formação de colágeno, fator importante no mecanismo de reparo de um defeito na região inguinal. Estes achados diferem de GOMES e col.. ${ }^{(25)}$ que utilizaram ratos machos e avaliaram a reação peritoneal induzida por duas próteses de polipropileno macroporosas e monofilamentares colocadas no espaço pré-peritoneal. Quando foram submetidos à eutanásia, no $30^{\circ}$ dia pósoperatório, os autores observaram que a formação de aderências, fibrose, reação inflamatória e de corpo estranho das próteses de polipropileno colocadas no espaço pré-peritoneal foram semelhantes àquelas do grupo controle, onde o espaço foi apenas divulsionado. BEETS e col.. ${ }^{(26)}$ implantaram em seis cadelas o mesmo número de próteses de polipropileno multifilamentar e seis próteses de polipropileno monofilamentar, em 12 regiões inguinais, por via laparoscópica transabdominal. Após três, seis, e doze semanas da implantação da prótese, constataram uma reação de corpo estranho de média intensidade, acompanhada da presença de células gigantes multinucleadas próximas à interface de prótesetecido, mais intensa com a implantação da prótese de polipropileno multifilamentar que da prótese de polipropileno monofilamentar.

Constatou-se no experimento que apesar da reação inflamatória leve ter ocorrido em todas as regiões inguinais do lado com prótese, a formação de aderências ocorreu em somente $30 \%$ dos casos, concluindo-se que existem fatores peculiares de cicatrização individuais que favorecem a formação destas aderências.

Apesar do uso corrente da prótese de polipropileno, inclusive no nosso experimento, DeBORG ${ }^{(27)}$ acredita que os futuros materiais devam ser mais resistentes à infecção e, quando colocados adjacentes às vísceras abdominais, devam ser incorporados aos tecidos em um processo de cicatrização adequada, porém sem provocar reação inflamatória intensa e persistente, além de fibrose excessiva e formação de cápsula fibrosa sobre a prótese. 
ARNAUD e col.. ${ }^{(7)}$ descreveram que as próteses de polipropileno provocam precocemente uma discreta infiltração linfocitária, acompanhada por formação de fibroblastos e produção de colágeno, caracterizando uma cicatrização de boa qualidade.

No nosso experimento, o lado A (com prótese) mostrou, aos trinta dias, o predomínio da proliferação de fibrócitos acompanhados de fibras colágenas, colágeno e tecido conjuntivo denso; a presença de células gigantes multinucleadas foi escassa, comprovando a reação inflamatória de leve intensidade, diferente de BEETS e col. ${ }^{(26)}$, que encontraram reação inflamatória de média intensidade. Mesmo assim, estes resultados reforçam o conceito de que a prótese de polipropileno estimula a fibroplasia necessária ao reforço na correção dos defeitos herniários, sem desenvolver reação de corpo estranho de grande intensidade, incompatível com a cicatrização adequada.

Apesar do estudo dispensar análise estatística face ao achado do zero matemático em um dos lados (lado sem prótese), o percentual de aderências em $30 \%$ dos casos em que se colocou prótese, mostrou um resultado significativo na avaliação das aderências, com o número de animais empregados.

Cabe aqui enfatizar os resultados obtidos na presente pesquisa, na qual, ao utilizar-se a prótese de polipropileno no espaço pré-peritoneal, em número limitado de animais, encontrou-se diferença na formação de aderências em relação ao lado controle, onde não havia a prótese.

Acreditamos que estudos posteriores em animais, com aplicabilidade em seres humanos devem ser feitos para avaliação dos benefícios e das desvantagens no posicionamento das próteses no pré-peritônio da região inguinal, bem como a manutenção desta linha de pesquisa em outros trabalhos experimentais.

\section{Conclusão}

A colocação da prótese de polipropileno por via de acesso anterior, no espaço pré-peritoneal da região inguinal, em cães, está associada a uma maior freqüência de aderências, além de reação inflamatória leve.

\section{Referências}

1. Rutkow IM, Robbins AW. Demographic classificatory and socioeconomic aspects of hernia repair in the United States. Surg Clin North Am 1993; 73:413.

2. Aydos RD, Silva IS, Goldenberg S, Goldenberg A, Simões MJ, Takita LC, Nigro AJT. Comparative study of polytetrafluoethylene and polipropilene mesh in laparoscopy repair of ventral hernias in rabbit. Acta Cir Bras 1999; 14:59-64.
3. Goldenberg A, Matone J, Marcondes W, Focchi G. Efeitos da tela de polipropileno no testículo, epidídimo e ducto deferente de cães. Acta Cir Bras 2001;16:226-30.

4. Waters DJ, Roy RG, Stone EA. A retrospective study of inguinal hernia in 35 dogs. Vet Surg 1993;22:44-9.

5. Bellón JM, Buján J, Contreras LA, San-Martin A.C, Jurado F. Comparison of a new type of polytetrafluoroethylene patch (mycro mesh) and polypropylene prosthesis (marlex) for repair of abdominal wall defects. J Am coll Surg 1996;183:11-8.

6. Taylor SG, Odwyer PJ. Cronic groin sepsis following tensionfree inguinal hernioplasty. Br J Surg 1999;86:562-5.

7. Arnaud JP, Eloy R, Adloff M, Grenler JF. Critical evaluation of prosthetic materials in repair of abdominal wall hernias. Am J Surg 1977;133: 338-45.

8. Durstein-Decker C, Brick WG, Gadacz TR, Crist DW, Ivey RK, Windom KW. Comparison of adhesion formation in transperitoneal laparoscopic herniorraphy techniques. Am Surg 1994;60:157-9.

9. Fitzgibbons Jr RJ, Salerno GM, Filipi CJ, Hunter WJ, Watson P. A laparoscopic intraperitoneal onlay mesh technique for repair an inguinal hernia. Ann Surg 1994;219:144-56.

10. Eller R, Bukhari R, Mcintire D, Jenevien E. Intraperitoneal adhesions in laparoscopic and standard open herniorraphy: experimental study. Surg Endosc 1997;11:24-8.

11. Chuback JA, Singh RS, Sills C, Dick LS. Small bowel obstruction resulting from mesh plug migration after open inguinal hernia repair. Surgery 2000; 127:475-6.

12. Speranzini MB, Deutsch CR. Biomateriais. In: Speranzini MB. Tratamento cirúrgico das hérnias das regiões inguinal e crural: estado atual . São Paulo: Atheneu; 2001. p.57-67.

13. COBEA. (Colégio Brasileiro de Experimentação Animal). Princípios éticos na experimentação animal. São Paulo. 1991. Disponível em: URL: www.meu site.com.br/cobea/index.htm.

14. Jenkins SD, Klamer TW, Parteka JJ, Condon RE. A comparison of prosthetic materials used to repair abdominal wall defects. Surgery 1983;94:392-7.

15. Gadacz TR, Jeffrey AC. Technology of prosthetic material. Sem Laparosc Surg 1994;2:123-7.

16. Greca FH. Influência da macroporosidade na biocompatibilidade de 02 telas de polipropileno usadas para correção de defeitos da parede abdominal: estudo experimental em cães [Tese]. Pontifícia Universidade Católica do Paraná; 1998.

17. Annibballi R, Fitzgibbons JR. Prosthetic material and adhesions formation. In: Arregui ME, Nagan, RF: in Inguinal hérnia: advances or controversies? Oxford: Radcliffe; 1994. p.11524.

18. Uscher FC. Hernia repair with marlex mesh. Arch Surg 1962;84:325-8

19. Layman TS, Burns RP, Chandler, Russel WL, Cook RG. Laparoscopic inguinal herniorraphy in a swine model. Am Surg 1993;1:13-9.

20. Brandão SC, Goldenberg S, Goldenberg A, Amaral DM, Pias VMS, Portella AO. Effects of expanded polytetrafluorethylene (PTFE-e) mesh, in the preperitoneal space introduced by videolaparoscopy in pigs. Acta Cir Bras 1998; 13 [serial online]. Disponível em: URL: [http://www.scielo.br/acb]

21. Walker AP, Henderson J, Condon RE. Double-layer prothesis for the repair of abdominal wall in a rabbit model. J Surg Res 1993;55:32-7.

22. Amid, PK, Shulman AG, Lichtenstein IL, Sostrin S, Young J, Hakakha. An experimental evaluation of a new composite mesh with the selective property of incorporation to the abdominal wall without adhering to the intestines. J Biomed Mater Res 1994;28:373-5. 
23. Jackson BB. Observations or intraperitoneal adhesions. Surgery 1958; 44: 507-14.

24. Spelzini RI, Brahin FA, Martínez CG, Muñoz de la Rosa S Experimental aspects of the integration process of prosthetic materials implanted at the abdominal wall. Rev Med Tucuman 1999;5:191-202.

25. Gomes CF, Time SCC, Bigolin S, Figueiredo TMS, Greca FH. Reação peritoneal mediante colocação de 2 tipos de próteses de polipropileno no espaço pré-peritoneal: estudo em ratos. Rev Med Paraná 1993;2:54-9.

26. Beets GL, Go PM, van Mamerm H. Foreign body reactions to monofilament and braided polypropylene mesh used as preperitoneal implants in pigs. Eur J Surg 1996; 162:823-5.

27. Debord JR. The rationale for selection of a prosthetic biomaterial in hernia repair. Probl Gen Surg 1995;12:75-8.

Melo RS, Goldenberg A, Goldenberg S, Leal AT, Magno A. Effects of polypropylene prosthesis placed by inguinotomy in the preperitonial space, in dogs: evaluation laparoscopic and microscopic. Acta Cir Bras [serial online] 2003 Jul-Aug;18(4). Available from URL: http://www.scielo.br/acb.

ABSTRACT - Purpose: Observing the effects produced by the prosthesis of polypropylene in the pré-peritoneal space in dogs Methods: 10 adult cross-bread dogs $(n=10)$ have been put trough bilateral inguinotomy where prosthesis was put on one of its sides. In the contra-lateral region, the procedure was the same, but without the use of prosthesis, serving as a control. After 30 days the animals had been submitted to a laparoscopic technique and a macroscopic evaluation was made via intraperitoneal besides being through a biopsy of fragments of the peritoneum to record histological alterations of the two inguinal regions. Results: Three of the animals presented adhesions in the local of the polypropylene prosthesis was placed. No animal presented adhesion in the local without prosthesis. The microscopically alterations in side A (with prosthesis) were characterized by the proliferation of dense fibrous conjunctive tissue, besides the lack of presence of giant multinuclear showing a light inflammatory reaction. Conclusion: The prosthesis of polypropylene induce the formation of adhesions, when placed in the pre-peritoneal space of dogs

KEY WORDS - Adhesions. Prostheses. Laparoscopy. Dogs.

Conflito de interesse: nenhum Fonte de financiamento: nenhuma

Correspondência:

Robério Silva Melo

Rua Desportista Humberto Guimarães, 347/802

57035-030 Maceió - Al

Data do recebimento: 14/03/2003

Data da revisão: 24/03/2003

Data da aprovação: 08/04/2003 